$\begin{array}{ll} & \text { Etnográfica } \\ \text { etnográfica } & \text { Revista do Centro em Rede de Investigação em }\end{array}$

Antropologia

vol. 12 (1) | 2008

Vol. $12(1)$

\title{
Outros nomes, histórias cruzadas: apresentando o debate
}

João de Pina-Cabral

\section{(2) OpenEdition \\ Journals}

\section{Edição electrónica}

URL: https://journals.openedition.org/etnografica/1589

DOI: 10.4000/etnografica.1589

ISSN: 2182-2891

\section{Editora}

Centro em Rede de Investigação em Antropologia

\section{Edição impressa}

Data de publição: 1 maio 2008

Paginação: 5-16

ISSN: 0873-6561

\section{Refêrencia eletrónica}

João de Pina-Cabral, «Outros nomes, histórias cruzadas: apresentando o debate», Etnográfica [Online], vol. 12 (1) | 2008, posto online no dia 19 junho 2012, consultado o 10 fevereiro 2022. URL: http:// journals.openedition.org/etnografica/1589 ; DOI: https://doi.org/10.4000/etnografica.1589

\section{(c) (1) (5)}

Etnográfica is licensed under a Creative Commons Attribution-NonCommercial 4.0 International License. 


\title{
Outros nomes, histórias cruzadas: apresentando o debate
}

\author{
João de Pina Cabral
}

Instituto de Ciências Sociais

Universidade de Lisboa

Março de 2008

EM GRANDE SERTÃO: VEREDAS, JOÃO GUIMARÃES ROSA MOSTRA-NOS como, nos nomes pessoais, a língua portuguesa é parte da constituição de cada um de nós (2001 [1956]). Nos nomes dos jagunços cujos traços o autor segue pelas veredas desse sertão, nas pessoas com quem eles se cruzam, assistimos à forma como a emoção constrói pessoas usando nomes, através de um processo dialogal de criação identitária em fluxo. A obra gira em torno a uma tragédia - a tragédia de um amor com três nomes. No jogo de identidades, valores e emoções que esta sucessão de nomes congrega, o escritor deita luz sobre processos de relevância universal: Reinaldo - nome de herói guerreiro, cuja face pública esconde algo; Diadorim - nome de confiança entre dois, cuja privacidade revela uma diferença sem revelar qual, nome que desliza congregando uma complexidade de inomináveis; Maria Diadorina - nome de morta cujo amor foi um desafio trágico à vida e cuja morte põe em causa o que foi preciso pagar para sobreviver. ${ }^{1}$

Em Todos os Nomes, José Saramago (1997) explora um armazém de nomes - um labiríntico cartório onde ficam os nomes dos que vivem, mas onde essa vida se vai perdendo em memórias que são, afinal, esquecimentos; em vidas que acabam sempre em mortes. O nome de cada um de nós é seu mas, ao mesmo tempo, insere-nos em relações de socialidade que nos ultrapassam em 
muito e que têm poder sobre nós. O nome é nosso, porém, só na medida em que pertence também aos outros que o identificam connosco. Nas deambulações sombrias do personagem principal assistimos a todo um caminho entre a vida e a morte, entre o público e o privado: entre o cemitério - onde estão os nomes dos mortos -, o cartório - onde os nomes dos vivos se tornam nomes de mortos - e a escola - onde os nomes dos vivos se tornam nomes públicos. $\mathrm{O}$ autor aprofunda esse jogo de vida e morte, de público e privado, em torno ao poder que os nossos nomes têm sobre nós.

Um olhar rápido à literatura em português revelará que a questão dos nomes é inesgotável e, pelos dilemas que lança, está muito viva. Em Moçambique, com João Paulo Borges Coelho (2004); no Brasil, com Ariano Suassuna (que, sobre o tema, tem grandes lições a dar, 2007 [1971]); em Angola, com O Vendedor de Passados de José Eduardo Agualusa (2004) ou com A Gloriosa Família de Pepetela (1997)... Ora, esses nomes (mesmo os que originam noutras tradições linguísticas - Mandimba, Wesley, Machel...) são nomes cujo referente linguístico básico é o português - essa língua que tanto nos vai unindo como separando dos dois lados do Atlântico, dos dois lados de África, por esse mundo fora...

Porque é que ainda ninguém se tinha perguntado: então, será que há algo de comum a todos nós que usamos nomes em contextos sociais onde o português é a principal língua de referência? É que, dessa forma, nós todos partilhamos um mesmo pano de fundo linguístico, histórico e cultural por relação a algo que, afinal, para todos nós, é tão essencial: saber quem somos!

Ser António Manuel da Silva Costa em São Paulo, no Vale do São Francisco, em Lisboa, no Alentejo rural, em Moçambique (Inhambane), em Goa, em Macau ou em Timor... será a mesma coisa? Em que medida é que esse nome terá o mesmo significado em todos esses tão distintos contextos? Será ele sempre o mesmo nome? Quando é que surgiu historicamente este modo de nomear pessoas que hoje identificamos com a lusofonia?² Que implicações sociais transporta essa tradição? Este é o desafio que fizemos aos autores do actual número temático da revista Etnográfica.

A presente recolha é o resultado de um esforço conjunto afro-luso-brasileiro no sentido de lançar um diálogo sobre uma questão que, afinal, é comum a todos nós: os nomes de pessoa em português. Organizado conjuntamente pelo Instituto de Ciências Sociais da Universidade de Lisboa e pelo Pagu - Núcleo de Estudos de Gênero (Unicamp, Brasil) em Setembro de 2006, o Simpósio Internacional Nomes e Pessoas: Género, Classe e Etnicidade na Complexidade Identitária ${ }^{3}$

2 E, já agora, a hispanofonia também, pois o sistema que usamos é essencialmente ibérico.

3 Realizado no âmbito do projecto "Nomes e Cores: Complexidade Identitária e Nomeação Pessoal na Bahia”, o simpósio foi generosamente subsidiado pela Fundação para a Ciência e a Tecnologia (MCTES, Portugal, POCI/ANT/61 198/2004) e pelo Instituto de Ciências Sociais da Universidade de Lisboa - entidades cujo apoio muito agradecemos. 
reuniu uma série de especialistas - nas áreas da antropologia sociocultural, da história e da sociolinguística - para discutirem este tema. Do simpósio resultaram duas colectâneas: uma tratando mais directamente das relações entre os nomes pessoais e alguns dos principais vectores de diferenciação social (género, etnicidade e família - vd. Pina Cabral e Viegas 2007); e a presente recolha, onde se aborda explicitamente a questão da antroponímia lusófona, tanto na sua perspectiva histórica como comparativa. ${ }^{4}$

\section{NOMES DE PESSOA}

Estudamos, pois, nomes. Mas não um tipo qualquer de nome - nomes de coisas, nomes de actos, nomes de lugares... não. Vamos tratar de algo que nos fascina a todos especialmente: o nosso próprio nome, nome de pessoa. Ora, estudar nomes de pessoa é estudar a pessoa - um dos conceitos analíticos mais abrangentes e consensuais que hoje possuímos para abordar, numa perspectiva universalizante, o ser humano enquanto ser sociocultural. ${ }^{5}$

As considerações seguintes inspiram-se na afirmação de Wittgenstein de que "As palavras só têm sentido no fluxo do pensamento e da vida." (em Needham 1985: 25) Urge, pois, prestar especial atenção à forma como os nomes pessoais são realmente usados em contextos linguísticos determinados, pelo que a abordagem que de seguida proponho é essencialmente antropológica.

Nomes são elementos da linguagem que "estão por objectos", no sentido que captam a singularidade de um objecto determinado sem, no entanto, o descreverem. ${ }^{6}$ Os nomes de pessoa são "nomes próprios"; quer dizer que, por meio deles, é designado um objecto singularmente determinado e não um tipo de objectos. Há que distinguir os nomes próprios, portanto, dos “nomes de espécie" mas também dos "nomes contáveis" - quer dizer, quando um nome próprio é apropriado para referir uma espécie (como, por exemplo, quando digo "ele é um Hitler"); ou ainda dos "termos de massa" (nomes como “ouro", "água”, etc.) que, em sentenças de identidade, funcionam como nomes de espécie.

Assim, quando tratado como um todo, o nome integral de uma pessoa lusófona (p. ex., António Manuel da Silva Costa) é um “nome próprio”. Contudo, há que sublinhar que as tradições euroasiáticas distinguem, no interior do

4 Tomo ocasião para agradecer a todos os que connosco participaram nesta empresa dos nomes, em especial quero deixar aqui expressa a minha profunda dívida para com Susana de Matos Viegas, Omar Ribeiro Thomaz e Heloísa Buarque de Almeida que, para além de excelentes colegas, se revelaram amigos verdadeiros.

5 Passada mais de uma década sobre a sua publicação, e apesar de muito ter sido escrito sobre o conceito de pessoa, considero que o debate reunido no livro de Carrithers, Collins e Lukes (1985) continua a ser o texto mais informativo sobre a matéria. Vide também Pina Cabral (2005a e 2007b).

6 O ainda recente ensaio de Adriano Naves de Brito (2003), sobre a semântica e ontologia dos nomes próprios, merece especial atenção e inspirou largamente as notas que seguem. 
nome de uma pessoa, entre nomes individuais e nomes familiares (sobrenomes).$^{7}$ Os primeiros são propriamente "nomes próprios" (e por isso nos referimos assim a eles) enquanto que os segundos são "nomes de espécie". Dito isto, ressalva-se que a forma de utilização conta. Assim, quando alguém se refere ao hipotético sujeito acima como "o Silva Costa", o sobrenome está a ser usado como um nome próprio.

O processo referencial que liga o nome ao objecto (neste caso um agente humano) é sempre provisório e rectificável e depende de todo um mundo de outras referências. Consideremos a tradicional pergunta que o padre faz aos padrinhos - "Que nome dar a esta criança?" Aí, "esta" é um termo ostensivo e "criança" é um termo descritivo. Mas, para que a comunicação funcione entre os vários agentes do ritual, eles têm que ter partilhado previamente uma série indeterminada de categorias: tanto sobre como identificar o que é "esta" por oposição a, por exemplo, "aquela”; quanto sobre como identificar o que é uma "criança" por oposição aos outros seres presentes. Ao apontar para a criança, o padre não está a apontar para o fatinho de renda, para a cruz peitoral, para a pia, para a pele da criança ou para os seus ossos, mas para o todo que constitui uma "criança" - um ser humano vivo que, portanto, integra uns e não outros destes aspectos mas não é redutível a qualquer um deles.

De facto, a comum experiência perceptiva de um qualquer objecto indeterminado não basta para assegurar a nomeação, porque não garante que seja possível identificar ou reidentificar futuramente esse mesmo objecto. O que constitui um objecto é a predicação - isto é, a sua relação com outros aspectos do mundo. ${ }^{8}$ Só que uma predicação que não esteja associada a uma indicação é cega (criança, "qual?"), da mesma forma que uma indicação sem predicação é vazia de significado (esta, "esta quê?"). Como insiste Adriano Naves de Brito, "Para ser baptizado, um objecto tem que estar suficientemente distinguido na multiplicidade dos dados da percepção. Não se pode baptizar um objecto para o qual não haja clareza sobre a sua identidade." (2003: 189)

Em suma, o uso dos nomes próprios presume uma série indeterminável de significados e é parasitário deles. Na verdade, como afirmou W. V. Quine, "não há enunciados singulares" (em Brito 2003: 125 e 195), pelo que, tal como as palavras nos dicionários, todos os conceitos são definidos por relação a outros conceitos. Se eu posso nomear alguém com sucesso é porque eu já partilho muitos outros significados com a pessoa com quem estou a comunicar. O que resulta disto é que a disposição a encontrar significado antedata a própria

7 Alerto ainda para o facto de que o termo "apelido" é o mais comum no português de Portugal e África e em espanhol para referir "nomes de família" ou "sobrenomes". Eu próprio evito usar a expressão "apelido", porém, já que, no Brasil, esta assumiu popularmente o significado de "alcunha", pelo que pode induzir em confusão.

8 "Um predicado é uma expressão que faz uma asserção sobre algo se a associarmos a uma outra expressão que está por aquilo sobre o que estamos a fazer a asserção.” (Geach em Brito 2003: 23) 
constituição individual dos significados particulares. Na verdade, os processos de constituição de significado presumem dois factores anteriores: a socialidade e a partilha de um mundo comum. Como explica Donald Davidson,

"A crença, a intenção e as outras atitudes proposicionais são todas sociais na medida em que são estados em que uma criatura não se pode encontrar sem ter o conceito de verdade intersubjectiva, e este é um conceito que não se pode ter sem partilhar um mundo com alguém, e saber que se partilha, assim como uma forma de pensar sobre esse mundo." (2001: 121)

Ora, como estamos a tratar especificamente de nomes próprios de pessoas, há que concluir que a constituição das pessoas individuais depende deste mesmo processo. Todo o conhecimento que possamos ter de nós próprios enquanto pessoa identificável por um nome próprio resulta da nossa inserção numa intersubjectividade que, por um lado, é socialmente constituída e, por outro, depende da partilha comum de um mundo ostensivo. A criança é baptizada antes de saber falar. Quando chega a conhecer-se a si própria, portanto, já se conhece por um nome que (por muito que, em algumas culturas, seja um nome de infância temporário) lhe foi sempre atribuído por outrem num contexto particular intersubjectivamente partilhado. Assim, "Não é importante se a referência é fixada por meio de descrições ou ostensão. A causalidade que liga os elos da cadeia de usos é relativa às intenções dos falantes no uso dos nomes próprios." (Brito 2003: 77)

A pessoa humana, portanto, não preexiste à sua condição social - tanto no reconhecimento corporal de si mesma como no seu "eu" (self, o seu sentimento de integração pessoal). Nesse sentido, a pessoa torna-se um sujeito activo no todo social na medida em que apela e é sujeita a apelação. O significado dos nomes pessoais para cada um de nós está directamente associado a uma dialéctica do comparecimento - i.e., o ter estado face a face com outros seres humanos nomeados, partilhando intersubjectivamente um espaço/tempo. Essa partilha nunca reduz a alteridade essencial da pessoa; a identidade de cada um está sempre ameaçada pela natureza necessariamente social do processo de constituição de significado. Nomear, por isso, é desde logo reivindicar - fazer exigências da pessoa (o que ressalta, por exemplo, do exemplo que nos é apresentado neste volume por Alcida Rita Ramos).

Voltemos ao baptismo, até porque, pela importância histórica que o cristianismo teve nos contextos de lusofonia, não corremos o risco de ser levados por distorções etnocêntricas. Ao responder ao padre, atribuindo um nome à criança, os pais ou padrinhos estão a realizar um acto constitutivo com um elevado teor de criatividade.

Constitutivo porque estão a criar um novo processo de reconhecimento de pessoa. Até há bem pouco tempo, aliás, o carácter constitutivo do baptismo 
era explícito - a criança não-baptizada não só se encontrava numa situação de grande instabilidade física como era tratada como sendo ainda pré-humana (cf. Pina Cabral 1989: 141-143). ${ }^{9}$ Mas a situação não se altera quando, em vez de eu baptizar, estiver simplesmente a atribuir a alguém uma nova alcunha ou um novo hipocorístico ${ }^{10}$ derivado do seu nome oficial. Também aí há constituição por meio de recontextualização. Nunca mais me esquecerei da fúria com que a minha tia reagiu quando, em criança, tentei atribuir um hipocorístico menos feliz ao meu primo mais jovem no decurso dos nossos jogos infantis. Essa fúria era a medida da natureza constitutiva do gesto que eu intentara.

Criativo porque as opções de escolha são sempre muito elevadas. Mesmo em Portugal, onde a série dos nomes próprios mais usados é relativamente pequena face a outros contextos lusófonos, a liberdade de escolha continua a ser considerável. O aspecto principal de criatividade, porém, é o facto de a escolha transportar sempre implicações semânticas - não só na etimologia do nome, na referência hagiográfica ou histórica ou na referência às modas vigentes mas, e sobretudo, pelo facto de a escolha de um nome criar serialidades (intergeracionais, no caso português em que as pessoas recebem o nome dos avós, dos padrinhos ou dos actores da moda; intrageracionais, no caso brasileiro em que os nomes de uma série de irmãos ou primos partilham todos de um elemento comum). Neste sentido, a tradição socioantropológica a que Robert Rowland se refere no início do seu ensaio (presente volume) e que tende a abordar os nomes pessoais como denotativos, reduzindo a relevância do seu teor conotativo, distorce profundamente o processo. ${ }^{11}$ Por exemplo, se escolho João Pedro ou Uólace para nome do meu filho, ${ }^{12}$ tal prende-se com o que eu "acho" sobre esses nomes, com a forma como os contextualizo semanticamente, com o futuro que desenho para o meu filho. O nome pessoal, em suma, é "significativo".

Mais uma vez a literatura fornece-nos exemplos úteis. No seu ensaio clássico sobre "Proust et les noms", Roland Barthes chamou a nossa atenção para o facto de os nomes dos personagens do grande escritor francês serem sempre "significativos" (1967). Através de uma série de processos (no caso de Proust relativamente discretos), o autor indica ao leitor algo sobre a natureza

9 Hoje, a teologia católica alterou-se devido ao impacto que nela teve a biologia contemporânea. Assim, ocorre um processo de atribuição de pessoalidade ao feto. Ainda é cedo para compreender todas as implicações teológicas desta profunda alteração. No referente aos nomes de pessoa, porém, algumas implicações podem já ser observadas - vd. Pina Cabral (2005b).

10 Hipocorístico - "Nome ou vocábulo que atenua, que é diminutivo de outro mais longo, indicando um tratamento carinhoso, de uso familiar ou infantil, e que é normalmente formado pela duplicação de sílabas" (Dicionário da Academia das Ciências).

11 Cf. Pina Cabral e Viegas (2007: 30-33); Bodenhorn e Vom Bruck (2006: 5-6).

$12 V d$. o seriado Cidade dos Homens (Globo, Rio de Janeiro), onde as implicações sociológicas desta escolha são brilhantemente exploradas. 
do personagem; evitando assim - ou, pelo menos, contornando - longas descrições possivelmente tediosas. O recurso ao humor ou à formalização sobre as características físicas ou sociais dos personagens é parte integrante da tradição moderna do romance realista. Ana Maria Machado leva a cabo uma exegese dos nomes das personagens de João Guimarães Rosa e aponta que tal poderia ser feito com proveito para os romances de muitos outros escritores famosos (1991 [1976]: 138).

Para a autora, o que ressalta da análise do processo é que o nome das pessoas ficcionais de Guimarães Rosa é polissémico e hipersémico. Quer dizer, há um processo cumulativo e cruzado de referências que leva a que os "ecos" dos nomes não são logo imediatamente patentes, nem fixos para todo o sempre, e continuam a reflectir-se refractariamente através do romance (ibidem: 19). Não só não existe um sentido único a decifrar, como o processo de decifração nunca está terminado. A recriação dos ecos nominativos, como poderíamos chamar ao processo, é constante através do romance e está sujeita a alterar-se em releitura.

Ressalvadas as devidas diferenças, creio que há muito a aprender com esta análise no referente aos processos de nomeação não-ficcional. No caso de alcunhas, o processo é em tudo semelhante. Já no caso dos nomes oficiais - os que recebemos no baptismo e/ou no registo civil - poderá parecer que os efeitos de eco nominativo são menos notórios ou, pelo menos, menos conscientes. Contudo, na minha própria investigação sobre nomes de pessoa, em Portugal, no Brasil e em Macau, acabei por compreender que, por trás da resposta "Escolhi esse nome para o meu filho porque é um nome de que eu gosto" ou "porque é muito bonito", existe todo um mundo de referencialidades submersas. Por vezes, a "incapacidade" para explicitar claramente esses ecos nominativos por parte dos agentes parecia funcionar até como uma maneira de proteger os nomeados contra a usura causada pelo facto de, ao dar uma resposta, se estar a excluir muitas outras - isto é, a necessidade de preservar a hipersemia.

As escolhas dos romancistas alertam-nos, portanto, para algo que é porventura menos explícito nos processos de nomeação pessoal quotidianos mas que está lá presente. Nesse aspecto, a conclusão principal que Ana Maria Machado retira do seu estudo dos nomes em Guimarães Rosa tem um significado, creio eu, universal. O nome próprio, diz ela, deve sempre ser visto como uma reminiscência. Para compreender o que pode estar a ser dito com este comentário vale a pena relembrar a definição do termo: "recordação vaga e imprecisa, em que predomina, geralmente, a componente afectiva" (Dicionário da Academia das Ciências).

Nas entrevistas que fizemos a jovens mães na Bahia sobre os nomes que escolhiam para os seus filhos, observámos dois aspectos centrais nas suas escolhas que remetem para o conceito de reminiscência: por um lado, a natureza vaga e imprecisa, submersa, dos ecos nominativos; por outro lado, a sua carga 
afectiva. Enquanto reminiscência, portanto, o nome pessoal viabiliza três processos identitários da máxima importância: o nome essencializa, na medida em que dá existência externa e durável a um processo de identificação pessoal que é sempre necessariamente evanescente; o nome cita, na medida em que remete sempre, de uma forma ou outra, para casos anteriores; e explora, na medida em que, através do processo constante de recontextualização dos ecos nominativos, se abrem novas pistas identitárias.

\section{NOMES EM PORTUGUÊS}

Ao abordar a antroponímia lusófona, os autores reunidos no presente número temático são necessariamente levados a pôr o enfoque sobre a alteridade: como divergem os nomes? como eram os nomes antes? que é que os faz diferentes entre si? que outros nomes há? como se conjugam e combinam as diferenças? Um elemento que os une é a procura de respostas a estas questões através do recurso a uma conjugação mais ou menos ajustada ao tema que cada um escolheu entre metodologias analíticas de cariz antropológico e metodologias de análise histórica.

O primeiro grupo temático, referente à história das práticas nominativas modernas em português, integra os ensaios de Robert Rowland e Nuno Gonçalo Monteiro. Conjuntamente, os autores abrem todo um novo campo do estudo historiográfico até aqui inexplorado entre nós. No primeiro caso, são estudadas as mudanças que ocorreram no sistema nominativo português na passagem da Idade Média para a Época Moderna; no segundo caso, as alterações que ocorrem em Portugal e no Brasil com a chegada ao poder da burguesia nacional na segunda metade do século XIX e inícios do seguinte.

Com estes estudos podemos compreender pela primeira vez como as mudanças nos sistemas de nomeação pessoal lusófonos acompanharam as grandes mudanças civilizacionais que instituíram novos regimes legais e políticos. Torna-se possível perceber que estas mudanças de regime, no sentido político da expressão, foram também mudanças no regime de constituição da pessoa humana - elas estão associadas a novas formas de integração no relacionamento entre a pessoa e o Estado, a Igreja, a família e a sociedade em geral.

Temos em seguida cinco ensaios que exploram a forma como o sistema de nomeação pessoal lusófono se relaciona com outras tradições, chegando a coabitar com elas de forma complexa e criativa. Passamos de um modo historicista de caracterização da tradição lusófona, para um modo contrastivo. Dois ensaios estudam casos de relacionamento com as tradições ameríndias brasileiras em contextos profundamente distintos: Alcida Rita Ramos observa como os Sanumá (Yanomami) usam os seus nomes "sob rasura", o que levanta particulares problemas quando estes se confrontam com formas lusófonas de usar nomes como objectos públicos; Susana de Matos Viegas, por outro lado, 
mostra como as práticas nominativas entre os índios Tupinambá da Bahia reflectem os processos de integração de diferentes tradições antroponímicas, por um lado, e de reivindicação de direitos sociais, por outro.

Os dois ensaios seguintes estudam casos de relacionamento entre o sistema lusófono e sistemas africanos: Wilson Trajano Filho, num magnífico ensaio de pendor tanto histórico quanto comparativo, coloca o enfoque sobre os processos de crioulização ocorridos no início do século XX na costa da Guiné, mostrando como os nomes que as pessoas usam reflectem e, ao mesmo tempo, produzem processos de intercâmbio e mutação sociocultural; por seu lado, Gregório Firmino estuda a forma como, durante os períodos tardo-colonial e pós-colonial, os Vatonga de Inhambane (Moçambique) criaram formas de nomeação que integram tanto as lógicas patrilineares nativas como os novos processos de nomeação associados à modernidade. Em seguida, no seu ensaio sobre Timor, Rui Graça Feijó apresenta material até hoje totalmente inédito sobre a forma como os timorenses reagiram à mudança política e social adoptando e manipulando distintos tipos de práticas nominativas.

Os três ensaios finais abordam a questão da diferença antroponímica de um outro ângulo: estudando processos de nomeação pessoal paralelos ao sistema oficial. Assim, Heloisa Pontes explora no seu ensaio a relação entre género e modernidade através dos nomes públicos das actrizes brasileiras da primeira metade do século XX. Piero de Camargo Leirner, por seu turno, mostra como os nomes de guerra dos militares brasileiros se inserem dentro de um sistema nominativo que é, de facto, global e, nessa medida, ultrapassa por completo as lógicas nacionais e lusófonas, sendo estruturado pela postulação abstracta do Inimigo. Finalmente, Mark Harris discute o potencial transgressivo das alcunhas que constituem veículos de continuidade cultural no Pará brasileiro dos períodos colonial e imperial.

O artigo final é uma tentativa de operacionalizar a já tão velhinha, mas ainda tão rica, metodologia antropológica da "comparação controlada". Aí, à luz de uma longa experiência etnográfica em vários contextos sociais onde a lusofonia é, por assim dizer, posta à prova do confronto com a diferença, eu próprio tento analisar quais as grandes linhas de força que integram o universo antroponímico lusófono como um universo de reminiscência.

\section{UM DESTINO DE ABERTURA}

“Na obra de Guimarães Rosa," diz-nos Ana Maria Machado,

os Nomes formam um sistema global de significação e, dessa maneira, desempenham um papel classificador. Ao mesmo tempo, significam em seu sistema a própria existência da significação, provando que não é possível falar em um sentido único para um texto, mas obrigando à incorporação 
de uma pluralidade de leituras - o que é completamente diferente de uma diversidade de interpretações, e é a manifestação do destino de abertura do texto. (1991 [1976]: 141)

Creio que, imersa nesta frase, está uma importante lição para compreendermos a forma como todos nós, através das nossas vidas, usamos nomes de pessoas: como recebemos os nossos nomes; manipulamos os nossos nomes; atribuímos nomes a outros; compreendemos os nomes deles; e, finalmente, alteramos os seus ecos nominativos através do uso. Em todas essas práticas, como demonstram os textos incluídos na presente recolha, manifestamos também um destino de abertura.

Os nossos nomes desempenham uma função classificatória, está claro; que seriam senão isso as listas telefónicas? Contudo, a importância que estas detinham há uns anos atrás como forma de situar uma pessoa numa cidade (e quantos de nós passámos horas debruçados sobre listas telefónicas?) parece ter-se finalmente esvanecido com os search motors internéticos. A procura de situar uma pessoa através de um sistema classificativo uninominal - que era um elemento integrante de tantos romances policiais e tantos romances de vida... durante toda a segunda metade do século XX - parece-nos hoje algo do passado.

Isto permite-nos até compreender com mais facilidade que um nome oficial não é um destino - compreender a natureza aberta da nominação. Mas há muito mais na lição dos romancistas. A pluralidade de leituras a que um nome se sujeita é um fenómeno aberto em constante recriação. No nosso quotidiano, deparamo-nos com uma diversidade de interpretações, claro. Ninguém interpreta o nome de outrem da mesma forma; há muito a saber para compreender o nome de qualquer um de nós. Aliás, por isso mesmo, quase todos gostamos tanto de falar sobre os nossos nomes; elaborando exegeses complicadas à mínima provocação; manipulando os seus ecos nominativos.

Há mais que isso, porém. É que os nomes de pessoas são por natureza enigmáticos. Todos sabemos que não sabemos tudo sobre o que levou à atribuição de um nome pessoal particular ou ao que outra pessoa poderá ler nele. Aí, a questão da hipersemia dos nomes de pessoa é da máxima relevância. A tal diversidade de interpretações é, afinal, muito mais que uma mera diversidade, ela é uma abertura.

Por contraste com a literatura, porém, no caso dos nomes de pessoas vivas, não se trata unicamente do destino de abertura de um texto; trata-se, outrosim, do destino de abertura de uma vida, ou melhor, vidas - já que, no jogar da interpretação de um nome (e esse jogo é permanente), está em causa a vida de quem é chamado mas também a de quem chama. Não é só a literatura que é "uma exploração do Nome", como dizia Barthes; também a nossa vida 
pessoal acaba por revelar esse constante jogo de reminiscência: os nomes exploram, citam e essencializam as pessoas.

"Eu chamo-me João" e "o meu nome é João": respondo a esse nome e sou proprietário desse nome. Mais que isso, porém, "eu sou o João". Em inglês, esse elemento essencializante é ainda mais patente quando nos identificamos dizendo: "This is João." Sem o nome seria difícil integrar a "coisa"; por isso, em praticamente todos os contextos socioculturais humanos até hoje conhecidos pela antropologia ocorrem cerimónias públicas de nomeação pessoal durante a primeira infância. Nessa medida, o nome tem um significado constitutivo que o diferencia radicalmente das outras formas policiais de "identificar" uma pessoa - como as impressões digitais, o desenho das pupilas ou o ADN.

\section{BIBLIOGRAFIA}

AGUALUSA, José Eduardo, 2004, O Vendedor de Passados. Lisboa, Dom Quixote.

BARTHES, Roland, 1967, "Proust et les noms", em To Honor Roman Jakobson: Essays on the Occasion of his Seventieth Birthday. Haia e Paris, Mouton.

BODENHORN, Barbara, e Gabriele Vom Bruck, 2006, "Entangled in histories: an introduction to the anthropology of names and naming", em Bodenhorn e Vom Bruck, (orgs.) The Anthropology of Names and Naming. Cambridge, Cambridge University Press, pp. 1-30. BORGeS COElhO, João Paulo, 2004, As Visitas do Dr. Valdez. Lisboa, Caminho.

BRITO, Adriano Naves de, 2003, Nomes Próprios: Semântica e Ontologia. Brasília, Ed. Univ. Brasília.

CARrITHERS, Michael, Steven Collins, e Steven Lukes (orgs.), 1985, The Category of the Person: Anthropology, Philosophy, History. Cambridge, Cambridge University Press.

DAVIDSON, Donald, 2001, Subjective, Intersubjective, Objective. Oxford, Clarendon Press.

GUiMARÃES ROSA, João, 2001 [1956], Grande Sertão: Veredas. 19. ${ }^{a}$ ed., Rio de Janeiro, Nova Fronteira.

MACHADO, Ana Maria, 1991 [1976], Recado do Nome: Leitura de Guimarães Rosa à Luz do Nome de Seus Personagens. São Paulo, Martins Fontes Ed.

NEEDHAM, Rodney, 1985, Exemplars. Berkeley, University of California Press. PePeTela, 1997, A Gloriosa Família. Lisboa, Publ. Dom Quixote.

PINA CABRAL, João de, 2007a, "A pessoa e o dilema brasileiro: uma perspectiva anticesurista", Novos Estudos CEBRAP, 78, pp. 95-112.

— Susana de Matos Viegas, op. cit., pp. 63-87.

—, 2005a, "Identidades inseridas: Algumas divagações sobre identidade, emoção e moralidade", Revista Portuguesa de Psicanálise, 26 (1), pp. 97-118. 
PINA CABRAL, João de, 2005b, “La soglia degli affetti: considerazioni sull'attribuzione del nome e la costruzione sociale della persona", Annuario di Antropología, 5 (6). Roma, Meltemi, pp. 151-172.

—_, 1989, Filhos de Adão, Filhas de Eva: A Visão do Mundo Camponesa do Alto Minho. Lisboa, Publ. Dom Quixote.

PINA CABRAL, João de, e Susana de Matos Viegas, 2007, Nomes: Género, Etnicidade e Família. Lisboa e São Paulo, Almedina.

SARAmagO, José, 1997, Todos os Nomes: Romance. Lisboa, Caminho.

SUASSUnA, Ariano, 2007 [1971], Romance d'A Pedra do Reino e o Príncipe do Sangue do Vai-e-Volta. 9. ${ }^{a}$ ed., Rio de Janeiro, José Olympio. 